\title{
الاختيارات الفقهية في تفسير الشيخ نووي الجاوي \\ وأثره في الحياة العملية في إندونيسيا
}

د محمد فردوس* , أ. د/ السيد عبد الحميد علي المهدلي **, د / سرينه بنت الحاج يحيى********, د/ فطريانا روشاي

*(Muhammad.firdaus@umt.ac.id), ${ }^{* *}$ (sayyed.almahdaly@unissa.edu.bn),

****(sarinah.yahya@unissa.edu.bn), ${ }^{* * * * *}$ (fitriana@umt.ac.id)

$$
\begin{aligned}
& \text { "المحاضر بقسم التربية الإسلامية بجامعة محمدية، تانجيرانج } \\
& \text { المحاضر بالجامعة الإسلامية السلطان الشريف على، بروناي دار السلام } \\
& \text { *******ماضر بالجامعة الإسلامية السلطان الشريف على، بروناي دار السلام }
\end{aligned}
$$

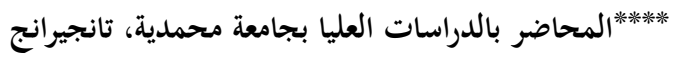

\section{ملخصص}

تحاول هذه الدراسة بصورة متواضعة على التعريف عن شخصية الشيخ نووي الجاوي، واتجاهه الفقهي من خلال تفسيره الموسوم "بمراح لبيد لكشف معنى قرآن بحيد". ولهذا التفسير دور عظيم في ترسيخ المذهب الشافعي في إندونيسيا خاصة، ودول جنوب شرقي آسيا عامة، حيث إنه مقدم للمقرر الرسمي عند المعاهد الإسالامية التقليدية أو الحديثة على حد سواء في إندونيسيا، والمؤسسات التعليمية والتربوية الإسلامية المنتشرة في أنحاء المعمورة. وكذلك في المحالس العلمية، بالإضافة إلى معظم المتحدثين والمباشرين فيها من الشافعية التي لا تدخر وسعا في نشر منهجهم، وترسيخه في عقول العامة. وفي آخر مبحث هذه الدراسة يبين الآثار التي تتبنى تطبيق المذهب الثافعي كنموذج في الحياة العملية ذات الصبغة الإسلامية في إندونيسيا.

\section{مقدمة}

هذه الدراسة تبرز معرفة شخصية الشيخ نووي الجاوي وابتحاهه الفقهي في تفسيره، ثم استعرض الباحث بعض الآيات القرآنية التيتعلقبالأحكام التكليفية التي اختلف الأئمة الفقهاء حولها، ثم يشير إلى الأقوال المختارة عند المذهب الثافعي التي هي من الاتجاه الفقهي عند الشيخ نووي الجاوي، مع ذكر الآثار في الحياة العملية ذات الصبغة الإسلامية في إندونيسيا. والمشكلات التي يواجهها الباحث في هذه الدراسة تأتي في المقام الأول تحديد أقوال الفقهاء قدماؤهم ومعاصرهم في ترجيح المسائل التي
يختلفون حوها، تم يظهر المذهب الشافعي فيها الذي استدل واختار به الشيخ نووي الجاوي مع بيان ذلك، ثم ذكر الآثار في الحياة العملية ذات الصبغة الإسلامية في إندونيسيا. وأما الأهداف، فهذه الدراسة التي تحاول أن تكشف عن السمة البالغة التي كان عليها المذهب الشافعي الذي تبناه شيخنا، مع ذكر آرائه الواردة في تفسيره، ثم إبراز الآثار في الحياة العملية ذات الصبغة الإسلامية في إندونيسيا نموذجا تطبيقيا للمذهب الشافعي. ومن أهمية هذه الدراسة هي إعانة المرء على معرفة المذهب الشافعي من خلال مساهمة الشيخفيه في تفسيره. وحدود 
هذه الدراسة هي الحدود الموضوعية، وهي تفسير الشيخ نووي الجاوي الموسوم مراح لبيد لكشف معنى قرآن بحيد، وذلك باستخراج المسائل الفقهية من العبادة والمعاملة والقضية العامة الواردة في التفسير، وجعل تفسيره نموذجاً للاعتراف على المذهب الشافعي منخلال التعامل المنهاجي مع الآيات القرآنية ودلالاتها المختلفة. والمنهج الذي نسير عليه في هذه الدراسة هو المنهج الاستقرائي التحليلي في جانب النظري والتطبيقي. وتتكون هذه الدراسة من أربعة مباحث: المبحث الأول: ملامح عن شخصية الشيخ نووي الجاوي. المبحث الثاني: ملامح عن تفسيره مراح لبيد لكشف معنى قرآن بجيد. المبحث الثالث: الاتجاه الفقهي عند الشيخ نووي الجحاوي في تفسيره من خلال مسائل العبادة والمعاملة والقضية العامة، مع بيان ذلك. المبحث الرابع: الآثار المترتبة في الحياة العملية في إندونيسيا مطابقة للمذهب الشافعي. المبحث الخامس:

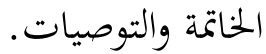

المبحث الأول: ملامح عن شخصية الشيخ

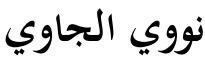
اسمه

هو أبو عبد المعطي محمّد نووي بن عمر بن عربي بن علي الجاوي البنتاني التناري، الشافعي المذهب، وذكر بعض المراجع أنّ نسبه متصل إلى الرسول ع

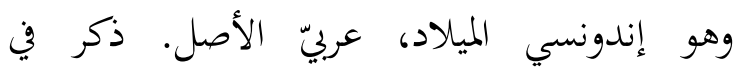
صفحات من تاريخ مكة فضل الشيخ نووي الجحاوي، أنّ الاسم نووي مأخوذ من اسم أحد أئمة الفقه الشافعي وهو الإمام النووي(صفحات عن تاريخ مكة المكرمة. ج2. صكئ.
ونسبه الأبوي هو نووي بن عمر بن عربي بن

علي بن جماد بن جانتا بن مسبوقيل بن مسقون بن مسوي بن تاج العرشي بانجيران سوبهياراراس بن مولانا حسن الدين (Pangeran Sunyararas) بن مولانا شريف هداية الله جيربون بن راجا أمة الدين عبد الله بن علي نور الدين بن مولانا جمال الدين أكبر حسين بن الإمام السيد أحمد شاه جلال بن عبد الله عظمة خحان بن عامر عبد الله ملك بن بن

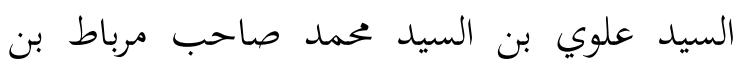
السيد علي خالي قاسم بن السيد علوي بن الإمام عبيد الله بن الإمام أحمد مهاجر إلى الله بن الإمام عيسى النقيب بن الإمام محمد النقيب بن الإمام محمد الباقر بن الإمام علي زين العابدين بن سيدنا حسين بن سيدتنا فاطمة الزهراء ينت محمّد رسول (Sayyid ulama Hijaz, syekh Nawawi له ع اللّ

alBantani)

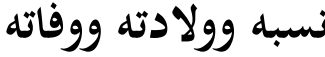

وهو من مواليد عام (1230ه) أي (1813م) في قرية تنارا التابعة لمحافظة بنتان إحدى المحافظات فن جزيرة جاوى إندونسيا. وكان أبوه عمر بن عربي قاضيا، وأحد العلماء في تنارا، وأمه زبيدة بنت محمد سنجاراجا التنارية الأصلية، وكان الشيخ نووي الجاوي أكبر ابن من سبعة الأشقاء؛ خمسة منهم ذكور، والباقي أنثيان، وعلى الترتيب أحمد شهاب الدين، وتميم، وسعيد، وعبد الله، وثقيلة، وسارية.

(99 kiai kharismatik Indonesia) وقد اشتهر نووي الجاوي كنيته بعبد المعطي، وكذلك "بسيد علماء الحجاز" بسبب انتشار Tradisi ) مؤلّفاته في كثير من دول الحجاز Pesantren. 
بأكمالها، وأمّا العلماء الأندونيسيون فلقّبوه بأبي كتب التراث الإندونيسي، كما لقب غيره من رجال العلم، بأنّه الإمام الفهّامة المدققّ، ولقبه المستشرق

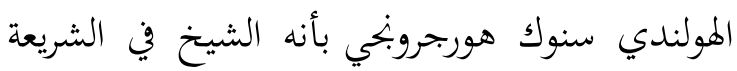

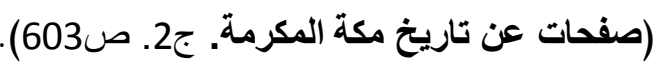
تربّ الشيخ نووي الجاوي على يدي أبيه؛ ولما

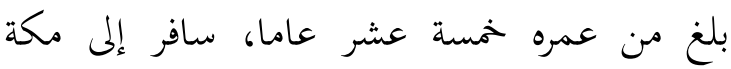
للحج، وأقام فيها ثلاث سنوات بين مكة والمدينة؛ ودرس على مشايخ الحرم المكي والمدني؛ ثم رجع إلى بلده إندونيسيا، وقام بالتدريس فن معهد أبيه، والتفّ حوله الطلاب ليستفيدوا من علمه، وبدأ ينتشر

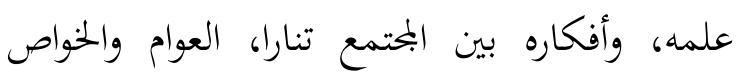

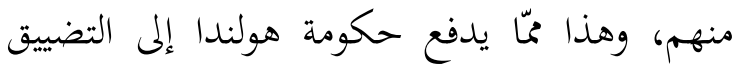
والضغوط عليه، فمنع الشيخ من إلقاء الخطب، لهبه

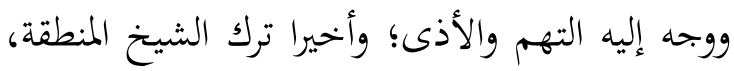

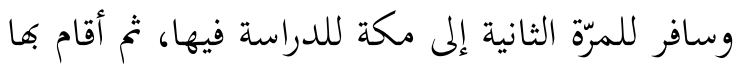
للتدريس والتأليف إلى أن توفي الشيخ محمد نووي إنداني الجاوي في (25 شوال 1314ه)، الموافق (1897) في منزله بشعب علي بمكة المكرمة،

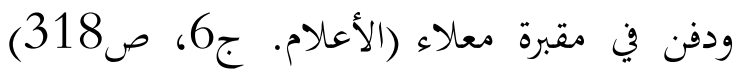

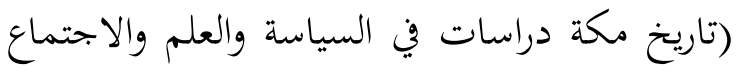
والعمران، الأمانة العامة للاحتفال بمرور مائة عام

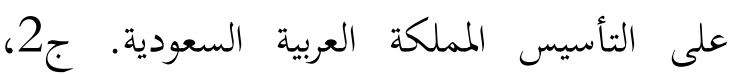

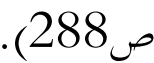

المبحث الثاني: ملامح عن تفسيره مراح لبيد لكشف معنى قرآن مجيد

لقد اشتهر هذا التفسير على ثلاث مسمّيات وهي: تفسير نووي، وتفسير المنير لمعالم التنزيل المسفر عن وجوه محاسن التأويل، وتفسير مراح لبيد لكشف معنى قرآن بحيد؛ وفي الأخير سمّي الشيخ وتشير مراح ليديد
نووي الجاوي تفسيره مع الموافقة لتاريخه "بمراح لبيد لكشف معنى قرآن بحيد"؛ أي: إنّ هذه التسمية مطابقة بترتيب حروف الهجاء عند الساميين(المعجم الوسيط. ج1. ص1)؛ أي عدد كميّة الأرقام للميع

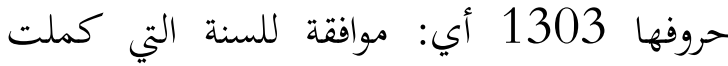
كتابة هذا التفسير في سنة 1303هـ، وقيل: في سنة 1305هـ الموافق 1887م. وقد اتفق الشيخ سيف ونيف

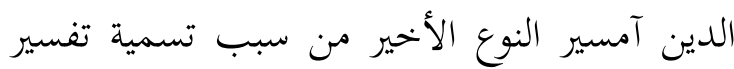

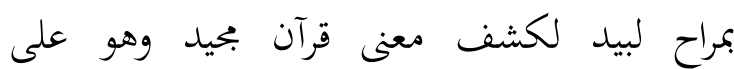
الحساب الهجائي. أهمية تفسير مراح لبيد لكشف معنى قرآن مجيد كتاب تفسير مراح لبيد لكشف معنى قرآن بجيد هو كتاب مختصر في تفسير القرآن الكريم، حقّقه

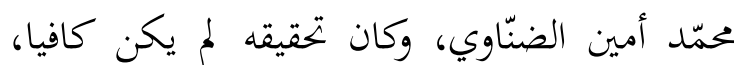
وكان موجزا، وإنه في حاجة إلى التطور حتى لا يقدح شخصه بذلك.

وسبب تفسيره: استعمل المؤلف خطبة الكتاب في مقدار صفحة واحدة، يبيّن فيها بعد الحمد لله تعالى، والثناء عليه، والصلاة والسلام على رسول الله ع. فقد التمس بعض أحبابه أن يكتب تفسيراً للقرآن المجيد، ولكنّ الشيخ الإمام تردّد زمنا طويلا،

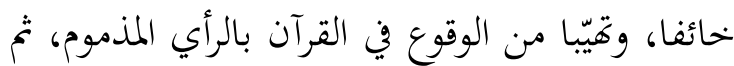

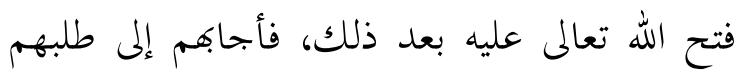

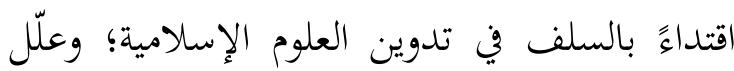
ذلك بقوله (ولكنّ ذلك عونًا لي وللقاصرين مثلي)

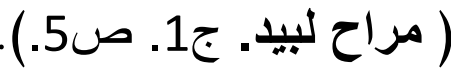

إنّ الشرط الأساسي لتفسير القرآن الكريم هو الإلمام

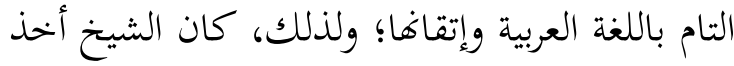

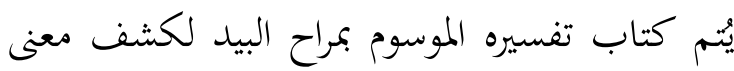

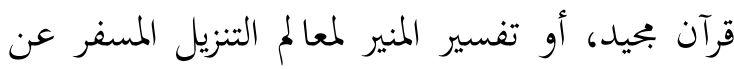


وجوه محاسن التأول على بحلدين، بعد أن تربّع بمكة المكرمة سنوات عديدة، وكان البحلد الأوّل منه يتكوّن من 672 (ستمائة اثنين وسبعين) صفحة، والبحلّد الثاني يتكون من 695 (ستمائة خمسة وتسعين) صفحة. وهذا الكتاب يشتمل على 30 (ثلاثين) جزءا من القرآن الكريم، المحلّد الأوّل منه يبدأ بسورة الفاتحة ويختتم بسورة الكهف (مراح لبيد. ج1. ص6726)، وأمّا البحلد الثاني فيبدأ بسورة مريم ويختتم بسورة الناس (مراح لبيد. ئ. ص6956)، أمّا دار النشر التي تلتزم بطبعه وإصداره مؤخرا هي دار الكتب العلمية بيروت لبنان، في سنة (1427هـ-2006م). شرع في تفسير مراح لبيد

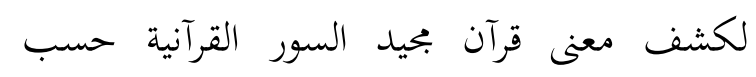
الترتيب المصحفي، بداية من سورة الفاتحة مع ذكر أسباب نزوها، وعدد آياقا، والكلمات، وحروفها، وعلم المناسبات بين الآيات والسور، ووجوه القراءات، وغير ذلك من العلوم التي تجلى المقاصد والمفاهيم للنص؛ وذلك إلى آخر السور القرآنية. ويُحتمل أنّ هذا التفسير ما يميزه عن غيره. إنّ ظهور هذا التفسير باللغة العربية، يمثّل تراثا علميّا قيّما تركه أحد أبناء هذا الربوع، لمفخّرة تستوجب الشكر لله تعالى على هذه المنّة، والحقائق

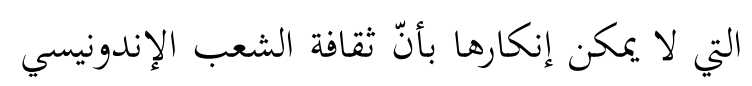

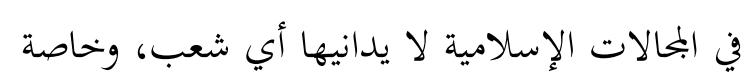
في جنوب شرقي آسيا، فضلا عن استخدام اللغة العربية في هذا المحال، وهو بالطبع يمثّل مزيّة يتمتّع

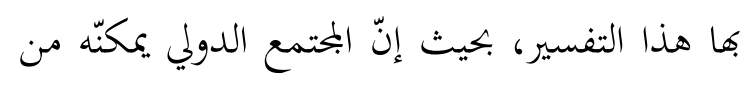

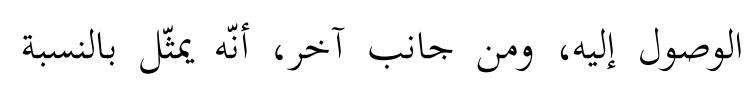

للمواطنين الإندونيسيين صفوة متازة، لعدم تمكّنهم من إتقان اللغة العربية. وجدير بالذكر أن أهميّة كتابة هذا التفسير يبلورها كون القرن التاسع عشر من الميلاد قد شهد

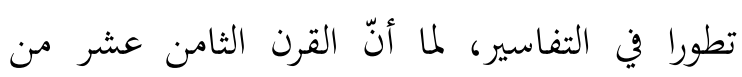
الميلاد لم يظهر في حيز الوجود في ربوع هذه البلاد ما عدا ترجمة القرآن 30 (ثلاثين) جزءا باللغة

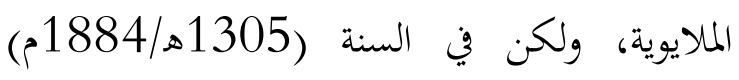
انبلج الفجر الجديد في بحال التفسير بظهور تفسير

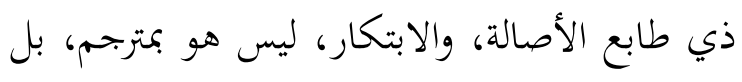
هو التفسير الذي يشمل الجوانب المختلفة من العلوم القرآنية من معاني المفردات القرآنية ومعنى الآيات على سبيل الإجمال، وأسباب نزولها وعدد أياها وكلمتها وحروفها ومن وجوه القراءات والمناسبات الآيات وغيرها من العلوم التي لها تعلق بالقضايا التي تحتويها الآية.

\section{القيمة العلمية للتفسير}

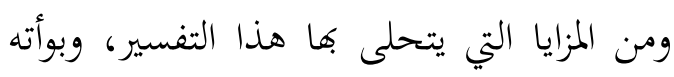
أن يكون في الصدارة، عناصره المكونة له في التعامل مع النصوص فقها وتفسيرا، وهي تعتبر لبنات منهاجية في التفسير التحليلي بالمفهوم الذي اصطلح عليه المتخصصون في هذا المجال، الذي يعد بكق سلما أساسيا لجميع الابتاهات والمناهج التفسيرية، وأهمها: الميزة الأولى: جمع كثير من العلوم بصورها مختصرة، تسهيلا على الطالبين وتقريبا للراغبين. كعلم القراءات، والروايات التفسيرية في معرفة الألفاظ القرآنية، وأسباب نزول الآيات، وعلم الناسخ والمنسوخ، وعلم المناسبات، والأخلاق الإسلامية، والقواعد اللغوية والفقه وأصوله غير ذلك. 
المزية الثانية :ذكر أقوال المفسيرين لإيضاح

معنى المراد. - م

المزية الثالثة : التعرف على المذهب الشافعي

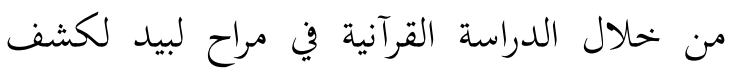
معنى قرآن بجيد، بكثرة وروده في الآراء المذهب

الشافعي، ولا يكون الشيخ متعصبا بمذهبه الشافعي تهراء

حيث رجحه أقوال المذاهب الأخرى، المثال ذلك

رجح الشيخ المذهب المالكي، وقال: (لا بيجوز

إطلاق يتيم على النبي ع لإشعاره بالتحقير، حتى

أفتى بعض المالكية بقتل قائله كما في الشفاء)

(مراح لبيد. ج1. ص629)؛ سكوت الشيخ من هذا

$$
\text { الرأي دليل على موافقته. }
$$

المبحث الثالث: الاتجاه الفقهي عند الشيخ

نووي الجاوي في تفسيره

الأولى : مسألة العبادة : التكبير في العيدين

\section{وإظهاره}

الآية المتعلقة بهذا الحكم قوله تعالى في سورة

البقرة:185. وقد استحب الإمام الشافعي العبادة

في ليلتي العيدين، أي: المسنونة. ومن ضمن تلك

العبادة في التكبير في ليلتيهما، والتكبير عند إكمال

صوم رمضان؛ وذلك إظهار شكر على ما هدى الله تعالى المؤمنين من قيام الفريضة، وإكماله مغيب

الشمس من آخر يوم من أيام شهر رمضان(الأم.

ج1. ص231).

ويستحب أن يكبر الناس جماعة، وفرادى في

المسجد، والأسواق، والطرق، والمنازل، ومسافرين،

ومقيمين، في كل حال، وأين كانوا، وأن يظهروا

التكبير، ولا يزالون يكبرون حتى يغدوا إلى المصلى،

وبعد الغدو حتى يخرج الإمام للصلاة ثم يدعوا
التكبير، وكذلك أحب في ليلة الأضحى لمن لم يحج(الأم. ج1. ص231). وقال في موضع آخر: يكون التكبير متواصل حتى جلس الإمام(الأم. ج1. ص231). واتفق الإمام الشافعي مع مذهب شيخه الإمام مالك، أن يكون التكبير في عيد الفطر مسنون فيه، وأصله الأضحى، أي: على ضبط إلى لهاب القياس في إظهار تكبير لمن لا يحج فيه(الإشراف على نكت مسائل الخلاف. ج1. ص342). واختلاف آخر يظهر على التكبير في عيد الفطر على ثلاثة أقاويل من العلماء الشافعية: أحدها: إلى أن يخرج الإمام؛ لأنه زمان التأهب للصلاة. الثاني: إلى إحرام الإمام؛ لأن الكام لا يحرم قبل إحرامه، فكان الاشتغال بالتكبير أولى.

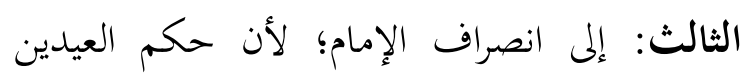
قضي بفراغه من الصلاة. وقال آخرون من الشافعية: إن كل ذلك يرجع إلى قول واحد، وليس باختلاف أقاويل، وإنما المراد

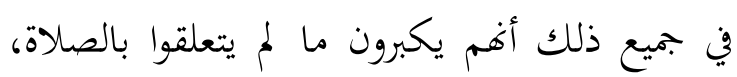
فتارة عبر عنه بالإحرام، وتارة عبر عنه بخروج الإمام؛ لأن خروجه يوجب الإحرام، وتارة عبر عنه بانصراف الإمام؛ لأن انصرافه يتعقب الإحرام(الحاوي في فقه

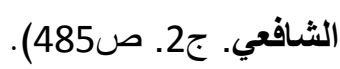
وأما التكبير في عيد الأضحى، فيإنه مقيد بالزمان، وهو تكبير أيام التشريق متعلق بالصلوات، فلم يعتبر لغيره. وقد أجيز تكبير فيه غير مقيد. وإن كبر في ليلتي العيدين، أي: الفطر والأضحى تكبيرا مقيدا، ففيه وجهان: أحدهما: أن يكون مضيا للسنة قياسا على يوم النحر، وأيام التشريق. والوجه 
الثاني: أن لا يكون متمثلا لما أمر به من سنة التكبير (الحاوي في فقه الثافعي. ج2. ص485). وكذلك عند الحنابلة، يسن التكبير المطلق،

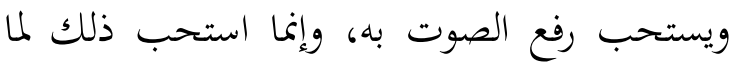
فيه من إظهار شعائر الإسلام وتذكير الغير، وكان ابن عمر يكبر في قبته بمنى، في سمعه أهل المسجدل،

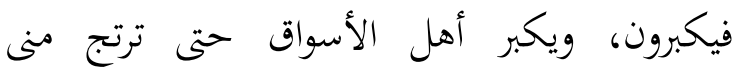
تكبيرا(الشرح الكبير على متن المقتع أبي عبد الله أحمد بن محمد بن حنبل الثيباني. ج2. ص251). وعند الحنفية لا يكبر في طريق إلى الجامع لصلاة عيد الفطر، ولا يتنفل قبلها مطلقا، ويعتبر رفع الصوت بالتكبير بدعة(الار المختار شرح تنوير الأبصار وجامع البحار. صنئن)، واستدل بقوله تعالى في سورة الأعراف:205، لأن الأصل في الثناء الإخفاء، إلا ما خصه الشرع كيوم الأضحى(تبيين

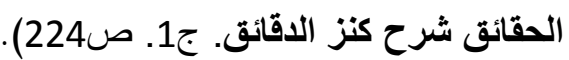
وأما الحديث ما رواه الإمام البيهقي، عن عبد البدان الله بن عمر: ((أن الرسول ع كَانَ يُكبِّرُ يَوْمَ الْفِطرِ

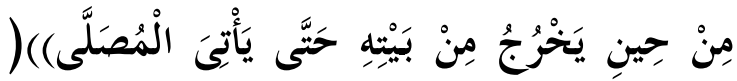

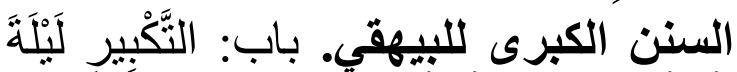

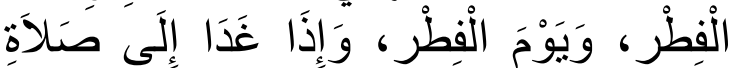

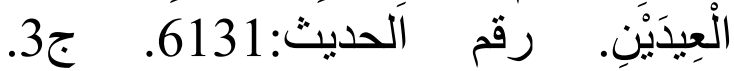

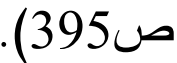

درجة هذا الحديث ضعيفة، أي: من سلسلات

رجاله ضعيفة منهم موسى بن محمد بن هن

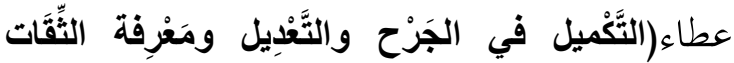

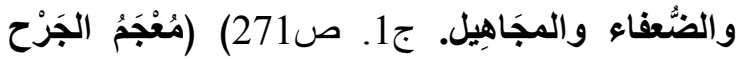

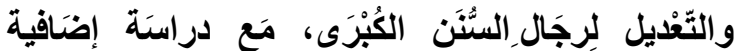

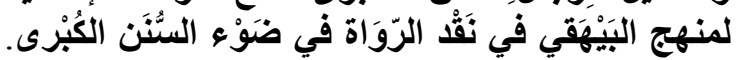

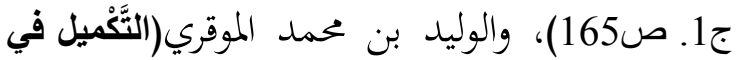

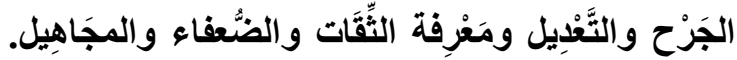

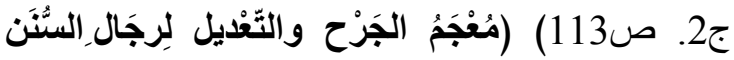

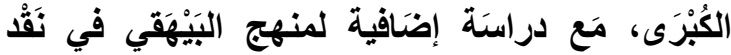

الرَّوَاة في ضَوُْ السَُنَن الكُبْرى. ج1. ص173)، ولم يصح لاستدلال(شرح فتح القير. بيروت: دار الفكر. ج2. (72). والمراد بالآية في سورة البقرة:185. هو صلاة عيد الفطر، وحكمها واجب عند الحنفية؛ لأن

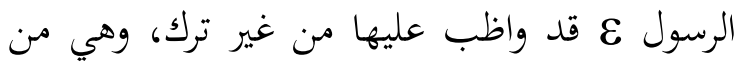
شعار الإسلام، وهذا دليل على الوجوب(تبيين

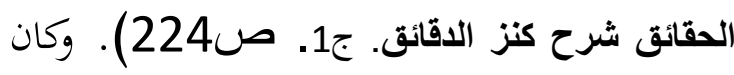

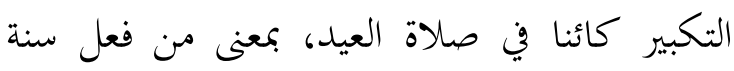
صلاة العيد وجب عليه التكبير؛ لأن إيجاب المشروط إيجاب الشرط(شرح فتح القدير. بيروت: دار الفكر. ج2. ص71). والإيضاح فيما اتجه شيخنا على المذهب الشافعي في التكبير، إنه عبارة عن إظهار الشكر لله تعالى على النعمة العظيمة، وهي علة التسهيل من كيفية القضاء على من لا يطيق الصيام بسبب مرض أو سفر، وهي رخصة من الله تعالى على عباده المؤمنين، وإظهار التكبير في العيدين من ابتحاه الفقهي عند الشيخ نووي الجاوي، ولعل هذا من باب التحدث بالنعمة(مراح لبيد. ج1. ص61). وهذه المسألة تبين أهلية الإمام الشافعي في وضع علوم الحديث، رواية ودراية، ليميز الصحيح

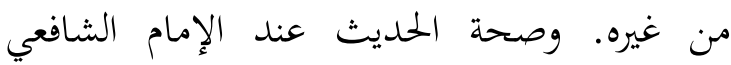
تنطبق على صحة الأسانيد، أي: سلسلة رجال

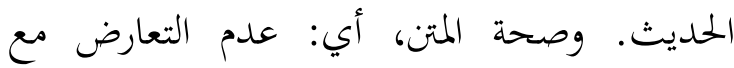
أصول التفسير العامة. وقوة الاستدلال به. ولذلك، ألكان

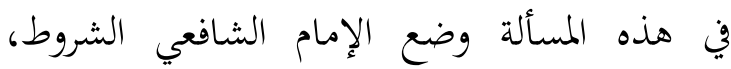
والضوابط عند اختلاف الحديث، أو عدم إمكانية

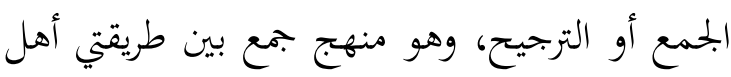

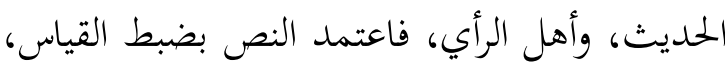


وأحكامه أولا، كما ذكر مسبقا في هذه المسألة، وقد أبان رسول الله ع سنتا عن الله معنى ما أراد بها؛ ثم

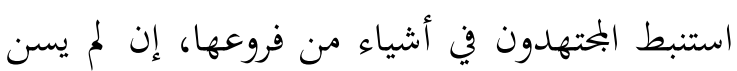

$$
\text { رسول الله فيها سنة منصوصة. }
$$
الثانية : مسألة المعاملة ولا شك في أن باب المعاملات في الفقه الإسلامي واسع، إلا أن الباحث في هذه الجزئية يكتفي بعرض طريقة الشيخ نووي الجاوي في علاج

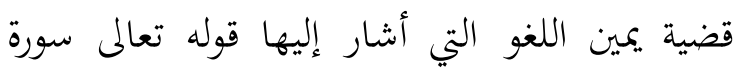
البقرة:225. لا ينعقد يمين اللغو حلفا أو اليمين

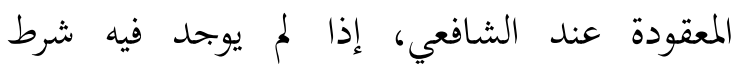

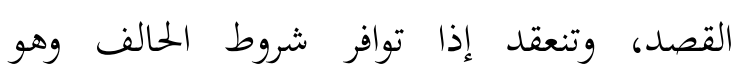
التكليف، والاختيار، والنطق، والقصد(حاثية إعانة

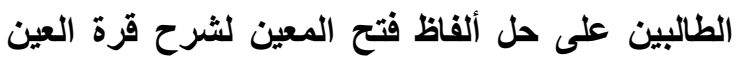

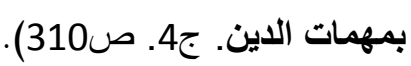
وقد ذكر الإمام الشافعي إن هذا من نوع اليمين

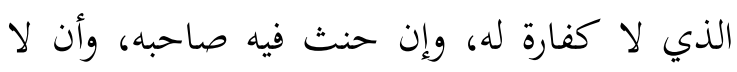
يكون عليه فيها إثم؛ لأن المرء لم يعقد فيها على إثم،

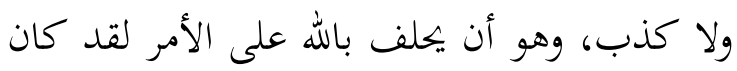

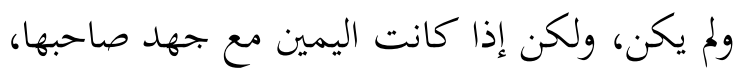
ومبلغ علمها، فذاك اللغو الذي وضع الله تعالى فيه

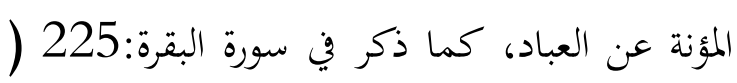

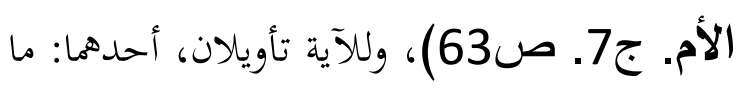

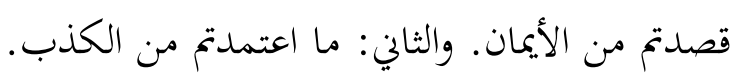
والله غقور، أي: لعباده فيما لغوا من أيماغم، الغان.

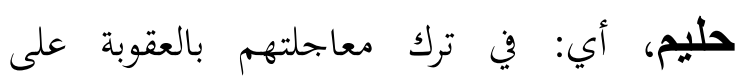
معاصيهم(الحاوي في فقه الثافعي. المرجع السابق. ج15. ص253). وقوله في سورة المائدة:89؛ فعقد الايمان هو

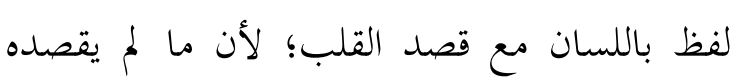

من أيمانه هو لغو لا يؤاخذ به، وفي عقدها تأويلان:

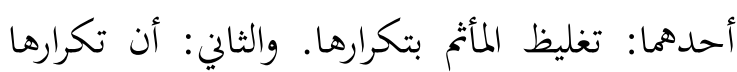
في المحلوف عليه إذا كان واحدا لم يلزم فيه إلا كفارة واحدة، وبه قال الإمام الشافعي في القديم يجب عليه

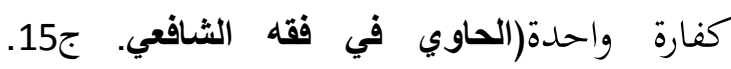
ص253.). وكذلك استدل الإمام الشافعي بما يذهب إليه، ما قالت أم المؤمنين عائشة رضي الله عنها: (لغو اليمين قول الإنسان لا والله، وبلى والله)

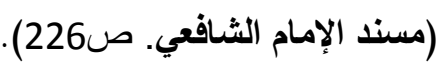
وهذا قول العرب، أي: اليمين التي لا يقصدها الحالف، ومثال ذلك كلامهم بلى والله، في الشراء والبيع وغير ذلك مما يؤكدون به كلامهم ولا يخطر ببالهم الحلف(مراح لبيد. ج1. ص78). وهو ماييري على ألسن الناس في كلامهم من غير قصد اليمين، سواء كان في الماضي أو الحال أو المستقبل(الإقناع

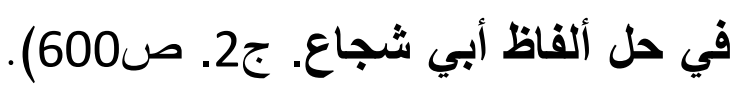
ودليله أنه ع وقد حلف عام الفتح، فقال: ((والله لأغزون قريشا، والله لأغزون قريشا، والله لأغزون إنه

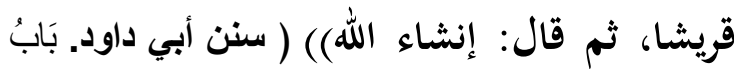

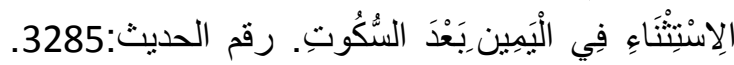
ج3. ص231). وروي أنه كان إذا أراد أن يحلف الفئف قال:(لالا والذي نفس محمد بيده)) (الآحاد

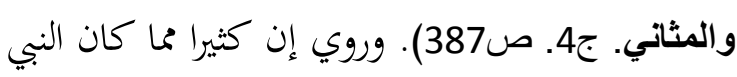
ع يحلف: ((لا ومقلب القلوب)) ( الجامع المسند

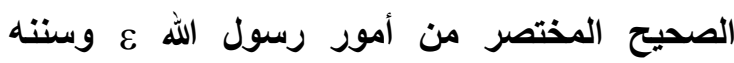
وأيامه. رقم الحديث:6617. ج8. صنافير المون). فإذ اتقرر هذا، فعقد اليمين موضوعة لتحقيق المحلوف عليه إن كان ماضيا، أول التزامه إن كان مستقبلا.

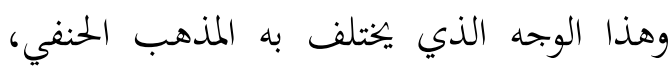
القائل: بأن لا لغو في المستقبل بل اليمين على أمر الكري 
في المستقبل يمين معقودة وفيها الكفارة إذا حنث قصد اليمين أو لم يقصد، وإنما اللغو في الماضي والحال فقط(بدائع الصنائع في ترتيب الثرائع. ج3.

ولم يفصل يمين اللغو عند الحنفية بين الماضي والمستقبل، فكان لغوا على كل حال إذا لم يقصده الحالف، ولأن الله تعالى قابل يمين اللغو باليمين المكسوبة بالقلب بقوله في سورة البقرة:225، والمكسوبة هي المقصودة، فكان غير المقصودة داخلا في قسم اللغو تحقيقا للمقابلة. وذكر قوله تعالى في سورة المائدة:89؛ قابل يمين اللغو باليمين المعقودة، وفرق بينهما في المؤاخذة ونفيها، فيجب أن تكون يمين اللغو غير اليمين المعقودة تحقيقا للمقابلة، واليمين في المستقبل يمين معقودة سواء وجد القصد

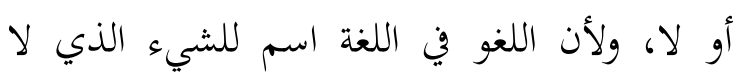
حقيقة له، بل على ظن من الحالف أن الأمر كما حلف عليه والحقيقة بخلافه. ولذلك، كل ما يجري على اللسان من غير قصد، لكن في الماضي أوالحال فهو مما لا حقيقة له، فكان لغوا؛ ولأن اللغو لما كان هو الذي لا حقيقة له كان هو الباطل الذي لاحكم له، فلا يكون يمينا معقودة؛ لأن اليمين المعقودة لهاحكم، والمؤاخذة فيها ثابتة وفيها الكفارة بالنص. وأما قول أم المؤمنين عائشة -رضي الله عنها- إن يمين اللغو ما يجري في كلام الناس لا والله، وبلى والله في الماضي لا في المستقبل(بلائع الصنائع في ثرثيب الشرائع.

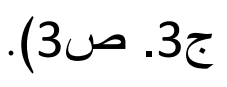

الإيضاح من قول شيخنا في هذا الحكم، إنه

النزم بمذهب الشافعي، حيث قال إن يمين اللغو لا تنعقد حلفا أو اليمين المعقودة عند الشافعي، إذا لم
يوجد فيه شرط القصد، وتنعقد إذا توافر شروط الحالف وهو التكليف، والاختيار، والنطق، والقصد، كما ذكرنا. وتعتبر غموسا إذا تكرر يمين اللغوي مع القصد، وهي تكون في الماضي والحال والمستقبل. ولا ينكر شيخنا على من تحلف في المسجد الحرام ألف مرة، ولعله قال: لا والله ألف مرة، بغير قصد ولا عليه المؤاخذة والمأثمة(مراح لبيد. ج1. ص70). ويبني هذا الكام على المذهب الشافعي، القائل أن العبرة في اليمين بنية الحالف؛ لأن المقصود من الأيمان هو المعنى القائم بالنفس، لا ظاهر اللفظ. وأما المقصود بالمحلوف عليه في اليمين، قال الشافعية: إن الأيمان مبنية على الحقيقة اللغوية، أي: بحسب صيغة اللفظ؛ لأن الحقيقة أحق بالإرادة والقصد، إلا أن ينوي شيئا فيعمل بنيته. ولذلك، صيكه يعتبر الحنث على من حلف أن لا يأكل لحما، فأكل شحماً، مراعاة لدلالة اللفظ(الفقه الإسلامي

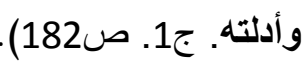
وقد حذر الشيخ نووي الجاوي من الهلاك على

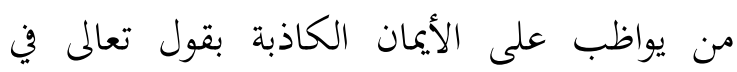
سورة التوبة:42، أي: بسبب الحلف الكاذب فإن الأيمان الكاذبة توجب الهلاك ولهذا، قال ع ع: ((اليمين الغموس تدع الديار بلاقع)) (مراح لبيد. ج1. ص443)، معناه: أن الله سبحانه وتعالى يفرق شمل الحالف، ويغير عليه ما أولاه من نعمه، وقيل: يفتقر ويذهب ما في بيته من المال(شرح السنة. ج1.

(85) الثالثة : القضايا العامة ويقصد بالقضايا العامة في هذه الدراسة هو ذكر المسائل التي اجتهد فيها الأئمة الأربعة، سواء كان الحكم على القياس أو المصلحة العامة. 
دخول الكافر المسجد

الآيات القرآنية المتعلقة في هذا الحكم هو قوله

تعالى في سورة التوبة:28. وقوله تعالى في سورة

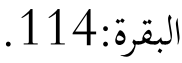

وقد اختلف الفقهاء في حكم دخول الكافر

المسجد، فقالت الشافعية بجواز دخول الكافر ولو غير كتابي المسجد بإذن المسلم، إلامسجد مكة وحرمها. وقال الإمام نووي: (لايمكن كافر من دخول حرم مكة، وأما غيره فيجوز أن يدخل كل مسجد ويبيت فيه بإذن المسلمين ويمنع منه بغير إذن) ( المجموع شرح المهذب. ج3. ص277-278). وعند الشافعية: يحرم دخول الكافر مسجد مكة وحرمها، ييجوز ما عداها من المساجد(الأم. ج1. ص54)، وقال ابن ملقن: جواز ربط الأسير وحبسه، وإدخال الكافر المسجد، واستدل بحديث عن أَبي

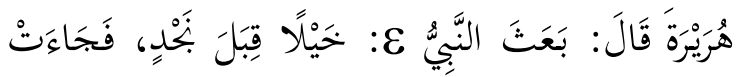

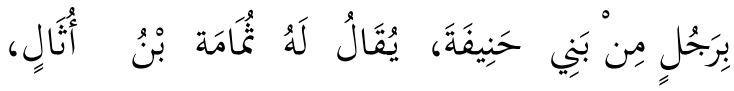

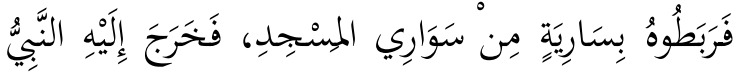

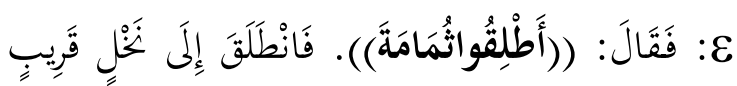

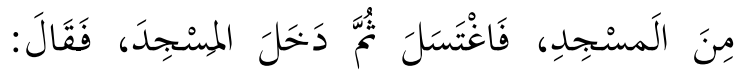

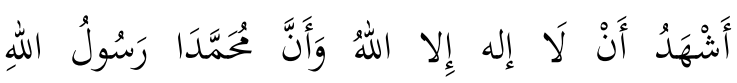
(التوضيح لثرح الجامع الصحيح. باب: الإغْتَسَّال إِذَا

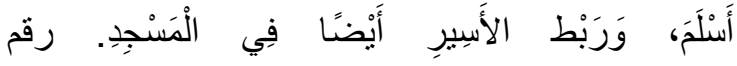

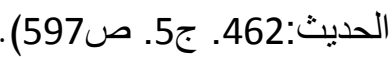

وأما أهل الذمة: لهم شرط في دخول مسجد المسلمين؛ لأنه إذا أغفل شرطه منع من دخوله لأكل ومنام لما فيه من التدنيس والتوسيخ. وكذلك إن لم يمنع منه المسلم، ولكن الأولى أن ينزلمم في غير المسجد، فإن أراد إنزالهم في المساجد اعتبرت حالهم. فإن خيف منهم تنجيس المسجد منعوا من نزوله،
وإن أمن منهم تنجيسه نظر فيه(الحاوي في فقه

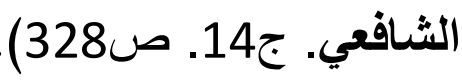
وعند الحنفية يجوز للكافر دخول المساجد كلها، واستدلوا بكون المشركين من وفود العرب وغيرهم كانوا يدخلون المسجد على رسول الله، فإنه روي أن أبا سفيان دخل المسجد عام الحديبية، وكذا وفد لِد ثقيف دخلوا المسجد، وقال رسول الله يوم فتح مكة من دخل المسجد فهو آمن، جعل عليه الصلاة والسلام المسجد مأمنا، ودعاهم إلى دخوله، وما كان عليه الصلاة والسلام ليدعو إلى الحرام (بائع الصنائع في ترتيب الشرائع. ج5. ص128). ويجوز كذلك دخول المسجد بغير إذن المسلم، واستدلوا بحديث ما روي عن الإمام الطبراني، أن المشركين لما رجعوا إلى مكة بعد غزوة بدر الكبرى، لمكي، فصعب عليهم الحياة، فتحدث في الأمربين عمير بن وهب الجمحي وصفوان بن أمية في الحجر كذا وكذا، وانطلق عمير نهو المدينة لقتل رسول الله ع، وضمنه على دينه، وعياله صفوان بن أمية، فأخبر الله تعالى سرّ حوار بين عمير وصفوان في الحجر، وما كان بينه وبين صفوان أحد، فأسلم عمير، وأسلم بيده كثير من أهل مكة (المعجم الكبير للطبراني. رقم الحديث: 119. ج17. صند5).

ومعلوم من هذا الحلديث أن الرسول ع لم ينكر

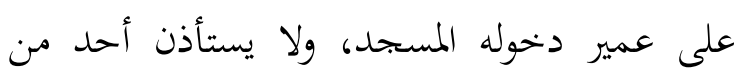
المسلمين حتى أخذه عمر بن الخطاب. ولأن من جاز له دخول المسجد لم يقف دخوله على الإذن،

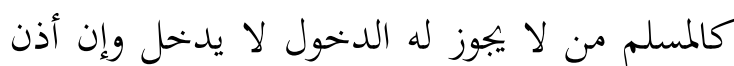
له، كالجنب والحائض. ولأن المنع من دخول البقعة إنما يكون لحق مالكها، والإذن إذا اعتبر في الإباحة 
اعتبر من جهة المالك دون غيره، وهذا لا يوحد في إذن غير الله تعالى (التجريد للقدوري. ج2. صالتحل). وأما الكتابي من أهل الذمة يجيوز لهم أن يدخلوا المسجد الحرام، واستدلوا بحديث الرسول ع: (لَالَا

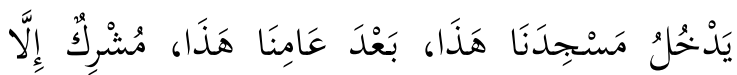

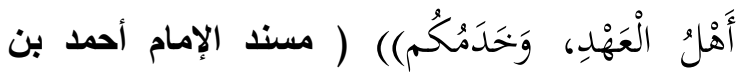

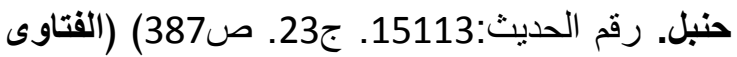
الهندية في مذهب الإمام الأعظم أبي حنيفة النعمان.

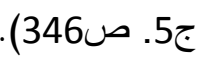

وأما النجاسة التي أطلقت على الكفار في الآية السابقة، فهي بناسة الاعتقاد لا الأبدان، وقال ابن بنيم الحنفي: (أما الآدمي، فلأن لعابه متولد من لحم

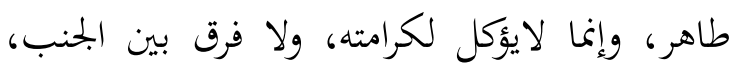
والطاهر، والحائض، والنفساء، والصغير، والكبير، والمسلم، والكافر، والذكر، والأنثى) ( البحر الرائق شرح كنز الدقائق. ج1. ص133). وعند المالكية، لا يجوز للكافر دخول مسجد الحل والحرم أصلا، ودليلهم أن الله تعالى لما منع الجنب والحائض دخول المسجد بقوله في سورة النساء:43، وذلك المنع تعظيم لحرمة المسجد، ومع أهما أقرب للطهارة. وأولى بالإباحة من الكافر، فامتناع الكافر من دخول المسجد أولى (الإشراف على نكت مسائل الخلاف. ج1. ص286). وعند الحنابلة لا يجيوز لكافر دخول الحرم مطلقاً، ولا مسجد الحل إلا لحاجة، كمسافر أو شبهه، وإن

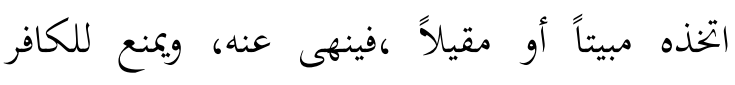
دخول المسجد الحرام، يمنع هو والذمي من استيطان الحجاز، ومن دخل منهم تاجرا أقام ثلاثة أيام، ثم ارتحل (حاثية الروض المربع شرح زاد المستقنع. ج4. ص317). وأمَّا دخول أهل الذمة المسجد، فإنّ
ذلك مكروه (الجامع لعلوم الإمام أبو عبد الله أحمد بن حنبل-الفقه. ج6. ص596). والبيان على ما استنبط عليه شيخنا في حكم جواز دخول كافر أو كتابي المسجد للأمن ومخافة القتل، ولا يزال الحكم على مهانتهم، وذلك بالقتل والسبي وضرب الجزية عليهم (مراح لبيد. ج1. ص40). المبحث الرابع: الآثار المترتبة في الحياة العملية ذات الصبغة الإسلامية في إندونيسيا هذه الدراسة والبحث عن المسائل الفقهية تعطي آثارا إيجابية قوية في الحياة العملية ذات الصبغة الإسلامية في إندونيسيا، بناء على أها من أكبر سكان المسلمين في العالمه وأكثر معاهد إسلامية التقليدية كانت أو الحديثة، والمؤسسات التعليمية والتربوية على المنهج الإسلامي المنتشرة في أنحاء المعمورة، وحدث عن المحالس العلمية المليونية ولا حرج، بالإضافة إلى معظم المتحدثين والمباشرين فيها من الشافعية التي لا تدخر وسعا في نشر منهجهم وترسيخه في عقول العامة. ومن خلال هذه النشاطات تظهر وحدة المسلمين بين الهيئات الدعوية الإسلامية المعاصرة في إندونيسيا، حيث إن وجودها يوقظ الأمة على إحياء ليالي شهر رمضان

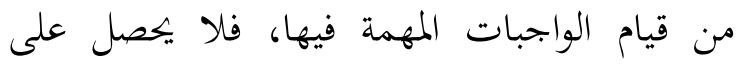
حقيقة الادعاء إلا بمراعاة أحكام الإسلامية الصحيتحة. ومن الأمر الذي يراود الإنسان منذ بدء الخليقة هو الحصول على الأمن والأمان، وذلك وجود الهان الاطمئنان في نفسه وأهله وبلاده، ومن الملوثات التي تفتضح على هذه الحالة هي وجود يمين الغموس بين أفراد البحتمع، وهي التي تبطل بها حقا وتحق بها 
باطلا، وبها تقطع مال مسلم ظلما، وسميت غموسا؛ لأغها تغمس صاحبها في النار (موسوعة مصطلحات التصوف الإسلامي. ص1065). وكذلك في يمين اللغو، ولو أها رجاء العفو، وينبغي للمسلم أن يتأكد على صحة قوله، وتقيدها في الماضي والحال باعتبار الغالب، وليس تقيد بالمستقبل كما ذهب إليه الإمام الحنفي، ولقد سمي اليمين المنعقدة وهي الحلف على الأمر المستقبل عند الحنفية. ولم تتعود ألسنة الشعب الإندونيسي على الشي استخدام كلمة القسم، ولم تكن منتشرة كما فعلها العرب، وذلك دليل على أن كلمة القسم لها آثار قوية في التحكم عند حدوث الخلاف بين الشعب الإندونيسي. وآخر بحث في هذه الدراسة هي دخول الكافر في المساجد؛ لقد اختار شيخنا المذهب الشافعي في ابتحاهه الفقهي، حيث يجيز دخول الكافر ولو غيركتابي المسجد بإذن المسلم، إلا مسجد مكة وحرمها. ونظرا إلى بحرى تاريخ تكوين دولة إندونيسيا، إن اسمها مأخوذة من اللغة اليونانية؛ هنديا أو هندوس، بكثرة أتباع الأديان الهندوسية، وكانت بلاد تحت نظام الممالك، وفيها المماليك الإسلامية، مثل مملكة آتجيه الإسلامية في جزيرة سوماطرا، ومملكة حسن الدين في بانتان جزيرة جاوى، وفي بعض الجزر من شرقي إندونيسيا مثل لومبوق، ومالوكو. ثم انتشر دين الإسلام بمجيء الدعاة من الجزيرة العربية بانتقال الحركة التجارية، ودخلت كثيرة من المماليك الهندوسية إلى دين الإسلام، ثم بنى مساجدا كثيرة، تعتبر هذه المساجد من التراث الإسلامي القديم في إندونسيا التي جاء إليها الزائرون السياحيون لممعرفة تاريخها القديمة من
الثراث الإسلامي. ولعل هذا الابحاه الفقهي كوسيلة لانتشار الفكرة الإسلامية بين الشعب والدول المختلفة. المبحث الخامس: الخحاتمة وأهم النتائج والتوصيات اختتم الباحث هذه الدراسة بقول الحمد لله، والشكر له على هذه المنة، وهي التعارف على لي لئ الشخصية الجليلة الشيخ نووي الجاوي البانتاني، ومساهمته في تدوين العلوم الإسلامية، وخاصة تفسيره المسماة مراح لبيد لكشف معنى قرآن بحيد، ومعرفة اتجاهه الفقهي من خلال هذا التفسير. وقد توصل الباحث إلى أهم نتائجها: 1. إن الشيخ نووي الجاوي يهتم كثيرا بالالتزام المذهبي وخاصة ابتحاهه إلى المذهب الشافعي، بكثرة توريده في كثير من مؤلفاته، وخحاصة تفسره، ويعتني به عناية فائقة لمقدمة على هذا المذهب، ودراسته من خلال الآيات القرآنية؛ لأكا تفتح أمام المسلم أوسع المحالات لفهم الاستدلال على المذهب الشافعي من خلال الآيات القرآنية.

2. قد وجد كثيرا من مؤلفاتالشيخ نووي الجاويما يدلى برأيه فهو ليس بحرد ناقل، بل

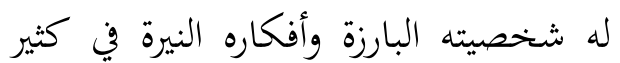
من البحالات العلمية. 3. وقد حث الشيخ نووي الجاوي على معرفة الاستدلا لكل المسائل الدينية، فيفتح المحال للاجتهاد على كل من له كفاءة العلمية الشرعية. وأما لعوام الناس الذين لا يمكنهم الحصول على العلوم الإسلامية بصورة مفصلة، فيصح لهم التقليد بأقوال العلماء 
والسلف الصالح. وأوجب على المسلم استعمال عقله عند إيمانه بالله تعالى، وغى ولى الكى عن التقليد في العقيدة. ولذلك، جعل العقل حكما في الإيمان بالله تعالى (نظام

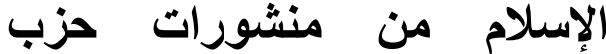
التحرير. ص98-8). وقال: وفي الأمور

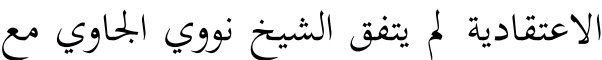
الإيمان التقليدي دون معرفة الاستدلال، ومعنى كونه تعالى ينادي عباده المؤمنين بشيء يطالب من خلاله الامتثال به، فإن ذلك لا يأتي إلا عن طريق التقليد مع معرفة الديل (أي: على سبيل التقلي التليد والاستدلال. انظر: نووي الجاوي.

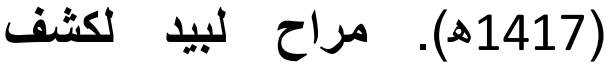
معنى قرآن مجيد. المرجع السابق.

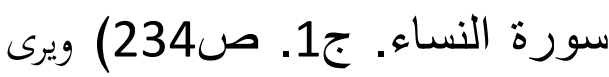
الباحث أنه في الحقيقة متبع لا مقلد من الناحية الأصولية؛ فشتان بين التقليد

$$
\text { ومن أهم التوصيات: }
$$

1. أوصي المسلمين من طلبة العلم أن يواصلوا

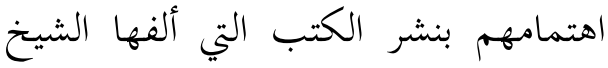
نووي الجاوي، خاصة تفسيره، والعلوم التي تتعلق بها بدراستها وأبحاثها بطريقة المنهجية العلمية.

2. التعرف على المذهب الشافعي من خلال

مؤلفات الشيخ نووي الجاوي، وذلك الكيكي

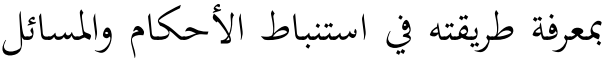
الفقهية.
3. تعلم مؤلفات الشيخ نووي الجاوي بمنهجية

التعليم المنضبط من معرفة عقيدة أهل السنة

والجماعة وهي عقيدة الأشاعرة والماتريدية،

ومذهبه الفقهي وهو المذهب الشافعي،

وتصوفه المعتدل.

وفي ختام هذه الدراسة أقول: إن هذه محاولة

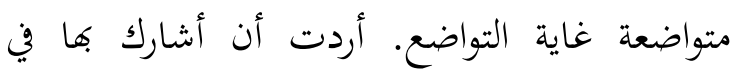
ميدان البحث العلمي، خدمة للدراسة القرآنية، وما أبرئ نفسي من القصور أو التقصير، فتلك شيمة الإنسان في كل مكان وزمان؛ ذلك لأن الكمال المطلق لله تعالى وحده. أما أعمال بني الإنسان فإِها

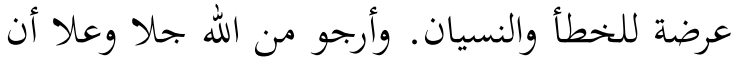

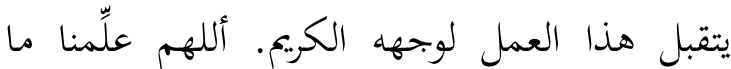

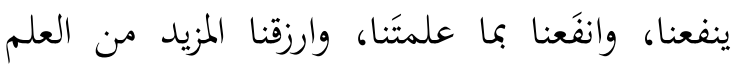
النافع والعمل الصالح. ربنا اغفرلنا ولوالدينا ولأساتذتنا ولمشايخنا وللمؤمنين والمؤمنات الأحياء منهم والأموات. والحمد لله رب العالمين.

Amin, Syamsul Munir.Sayyid $\overline{\text { Ulama }}$ Hijjaz -Biografi Syekh Nawawi Al Bantani. Pustaka Pesantren: Yogyakarta, 2009.

Musyhuri, Ustadz Ahmad Aziz. 99 kiai kharismatik Indonesia. Kitab Yogyakarta. (Eds) (2. 2008).

Nurul Huda 'sekilas tentang kiyai Nawawi Albantani.Alkisah.No: 14 ، 4 september 2003.

ابن الملقن، سراج الدين أبو حفص عمر بن علي بن

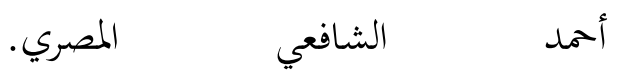

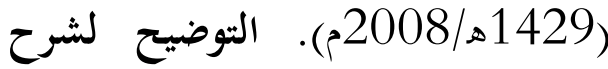

الجامع الصحيح. المقق: دار الفلاح

للبحث العلمي وتحقيق التراث. دمشق سوريا: دار النوادر. ط1. 
ابن خلكان، أبو العباس شمس الدين أحمد بن محمد بن أبي بكر. (د.ت.) وفيات الأعيان. إحسان عباس (محقق). بيروت: دار صادر. د.ط

ابن قدامة المقدسي، شمس الدين أبي الفرج عبد

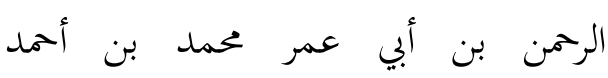

(د.ت.). الثرح الكبير على متن المقنع أبي عبدالله أحمد بن محمد بن حنبل الثيباني. دار الكتب العربي.

ابن كثير، أبو الفداء إسماعيل بن عمر القرشي البصري الدمشقي. (1432هـ/2011م). التَّكْميل في الجَرح والتَّعْدِيل ومَعْرِفة التَّة

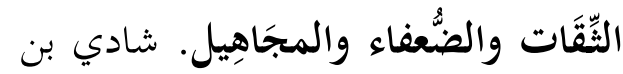
محمد بن سالم آل نعمان (محقق). اليمن: مركز النعمان لبحوث ل والدراسات الإسلامية وتحقيق التراث والترجمة. ط1 1. أبو الحسين القدوري، أحمد بن محمد بن أحمد بن جعفر بن حمدان. (1427هـ/2006م). التجريد للقدوري. مركز الدراسات الفقهية والاقتصادية: محمد أحمد سراج. علي جمعة محمد (محقق). القاهرة: دار السلام. $.2 b$

أبو السعود، محمد بن محمد العمادي. (د.ت.). إرشاد العقل السليم إلى مزايا القرآن الكريم. العربي-بيروت: دار إحياء التراث.

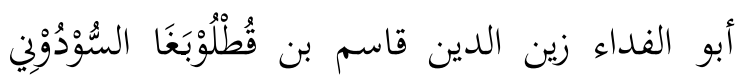
(نسبة إلى معتق أبيه سودون الشيخوني) الجمالي الحنفي ت879ه. الثقات ممن لم يقع في الكتب الستة -يُنشر لأول مرة

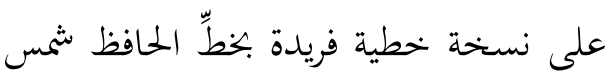

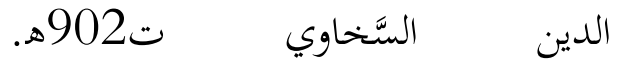

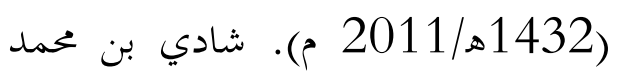
بن سالم آل نعمان (محقق). اليمنصنعاء : مركز النعمان للبحوث والدراسات الإسلامية وتحقيق التراث والترجمة. ط1 1. أبو بكر الشيباني، أحمد بن عمرو بن الضحاك. 1411هـ/1991م). الآحاد والمثاني. باسم فيصل أحمد الجوابرة (محقق). الرياض: دار الراية. ط1. أبو داود سليمان بن الأشعث بن إسحاق بن بشير بن شداد بن عمرو الأزدي السِّرِِِّنتاني (د.ت.). سنن أبي داود. محمد محيي الدين عبد الحميد (محقق). صيدا-

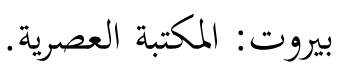
أبو عبد الله الشافعي، محمد بن إدريس. (د.ت.).

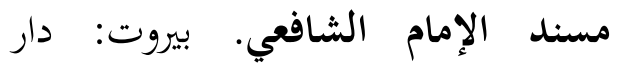
الكتب العلمية. د.ط إسم

أحمد بن حنبل. (1420هـ/1999م). مسند الإمام أحمد بن حنبل. شعيب الأرنؤوط وآخرون (محقق). مؤسسة الرسالة. ط2. إسماعيل بكر، محمد المصري الأزهري. (1411هـ/1991م). دراسات في علوم القرآن. القاهرة: دار المنار. ط1. البخاري، محمد بن إسماعيل بن إبراهيم بن المغيرة البخاري، أبو عبد الله. (1422هـ). الجامع المسند الصحيح المختصر من أمور رسول الله صلى الله عليه وسلم وسننه وأيامه. محمد زهير بن ناصر الناصر (محقق). دار طوق النجاة. ط1 1 (مترك. 
البغوي، أبو محمد الحسين بن مسعود بن محمد بن

الفراء البغوي الشافعي (1403هـ-

1983م). شرح السنة. شعيب الأرنؤوط

ومحمد زهير الشاويش (محقق). دمشق-

$$
\text { بيروت: المكتب الإسلامي. ط2. }
$$

البيضاوي، ناصر الدين أبي الخير عبد الله بن عمر الإسي

بن محمد الشيرازي الشافعي (د.ت.). أنوار

التنزيل وأسرار التأويل، المعروف بتفسير

البيضاوي. إعداد وتقديم: محد عبد

الرحمن المرعشلي. بيروت-لبنان: دار إحياء

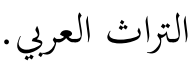

البيهقي، أحمد بن الحسين بن علي بن موسى لـ بري،

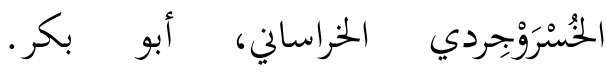

(1424ه/2003).

محمد عبد القادر عطا (محقق). بيروت-

لبنان: دار الكتب العلمية. ط3.

الجوهري، أبو نصر إسماعيل بن حماد. الصحاح تاج

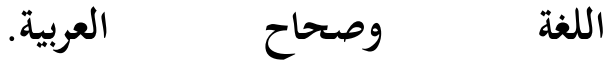

(1420هـ/1999م). إميل بديع يعقوب

(محقق). محمد نبيل طريفي (محقق).

بيروت-لبنان: درا الكتب العلمية. ط1.

الحلبي، نور الدين محمد عتر. (1414هـ/19931).

علوم القرآن الكريم. دمشق: مطبعة

$$
\text { الصباح. طـ } 1 .
$$

الحميدي، محمد بن فتوح. (1423هـ/2002م).

الجمع بين الصحيحين البخاري ومسلم.

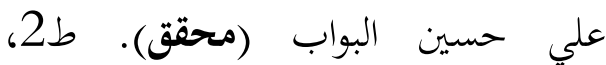

$$
\text { لبنان-بيروت: دار ابن حزم. }
$$

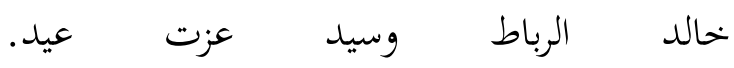

(1430هـ/2009). الجامع لعلوم
الإمام أبو عبد الله أحمد بن حنبل-

الفقه. القيوم-جمهورية مصر العربية: دار

الفلاح للبحث العلمي وتحقيق التراث.

$.1 b$

الخطيب، محمد الشربيني. (1415ه). الإقناع في

حل ألفاظ أبي شجاع. بيروت: دار

الفكر.

خلف، بنم عبد الرحمن. (1409هـ/1989م).

مُعْجَمُ الجَزح و والتّعْديل لِرِجَال السُّنَن

الكُبْرى، مَعدراسَة إضَافية لمنهج

البَيْهَقِي في نَقْد الرّوَاة في ضَوْهُ السُّنَن

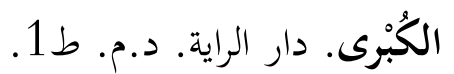

الدمياطي، أبو بكر ابن السيد محمد شبطا.

(د.ت.). حاشية إعانة الطالبين على حل

ألفاظ فتح المعين لشرح قرة العين

بمهمات الدين. بيروت لبان: دار الفكر.

الذهبي، الإمام شمس الدين أبي عبد الله محمد بن

أحمد بن عثمان. (1418هـ/1997)م)

طبقات القراء. د. أحمد خان (محقق).

المملكة العربية السعودية - مركز الملك

فيصل للبحوث و والدراسات الإسلامية.

.15

الذهبي، شمس الدين أبو عبد الله محمد بن أحمد بن

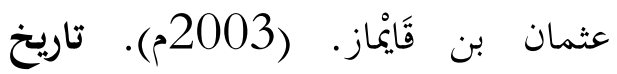

الإسلام وَوَفيات المشاهير وَالأعلام.

بشار عوّاد معروف (محقق). دار الغرب

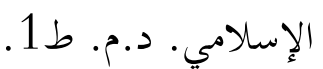

الزركلي، خير الدين بن محمود بن محمد بن علي بن

فارس الدمشقي. (2002م). الأعلام.

دار العلم للمالايين. د.م. ط15. 
الزيلعي الحنفي، فخر الدين عثمان بن علي.

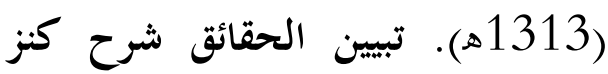
الدقائق. القاهرة: دار الكتب الإسلامي. تهن الحمات ترح . د.

السباعي، أحمد. (1419ه). تاريخ مكة دراسات

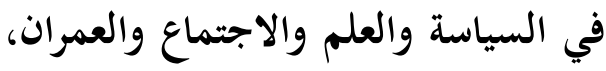
الأمانة العامة للاحتفال بمرور مائة عام ولعم ولادماع على التأسيس المملكة العربية السعودية. الرياض: فهرسة مكتبة الملك فهد الوطنبة.

. b.

السيوطي، الدين.

(1404هـ/1983م). تناسق الدرر في الإم الدال

تناسب السور. عبد الله محمد الدرويش

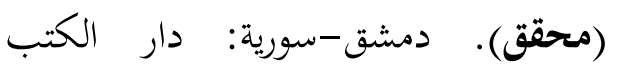

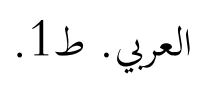

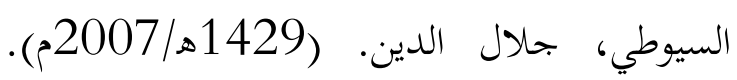

الإتقان في علوم القرآن. شعيب الأرنؤوط

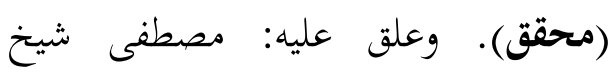

مصطفى. بيروت-لبنان: مؤسسة الرسالة.

$$
\text { 1. }
$$

الشافعي، محمد بن إدريس أبو عبدالله. (1393هـ).

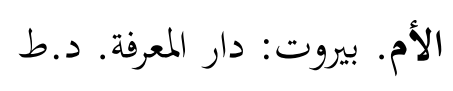

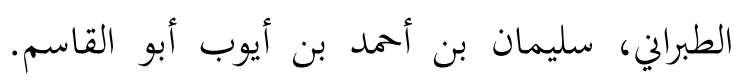

(1983/1404هـ)

حمدي بن عبد البميد السلفي (محقق).

الموصل: مكتبة العلوم والحكم. ط2 الحيد.

العاصمي الحنبلي النجدي، عبد الرمن بن محمد بن

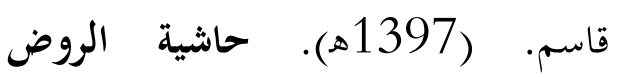

المربع شرح زاد المستقنع. ط1. د. د.م.
العالمكيرية، الشيخ نظام وجماعة من علماء الهند. (1411هـ/1991). في مذهب الإمام الأعظم أبي حنيفة

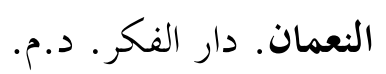

عبد الواحد السيواسي، كمال الدين محمد (د.ت. ). شرح فتح القدير. بيروت: دار الفكر. د.ط.

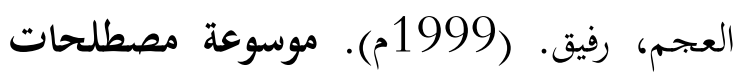
التصوف الإسلامي. بيروت-لبنان: مكتبة لبنان. .16 علاء الدين الحصكفي الحنفي، محمد بن علي بن

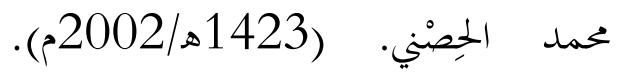
الدر المختار شرح تنوير الأبصار وجامع البحار. عبد المنعم خليل إبراهيم (محقق). دار الكتب العلمية. ط1 العبد.

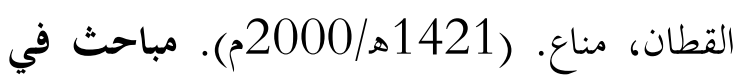
علوم القرآن. مكتبة المعارف. ط3. د. د.م. الكاساني الحنفي، علاء الدين. (1982م). بدائع الصنائع في ترتيب الشرائع. بيروت: دار

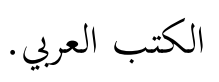

الماوردي، أبو الحسن علي بن محمد بن محمد بن المربن

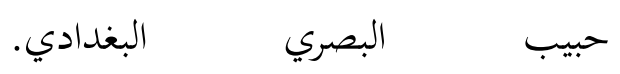

(1414هـ/1994م). الحاوي في فقه البصري

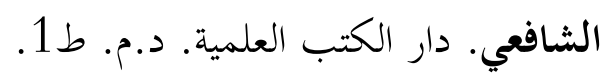

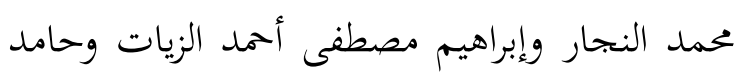
عبد القادر. (د.ت.). معجم الوسيط. مجمع اللغة العربية (محقق). دار الدعوة. المناوي، محمد عبد الرؤوف. (1410هـ). التوقيف على مهمات التعاريف. محمد رضوان 
الداية (محقق). بيروت-دمشق: دار الفكر

$$
\text { المعاصر ودار الفكر. ط1 1. }
$$

النبهاني، تقي الدين. (1372هـ/1953م). نظام

الإسلام من منشورات حزب التحرير.

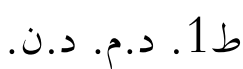

النسفي، أبو البركات عبد الله بن أحمد بن محمود.

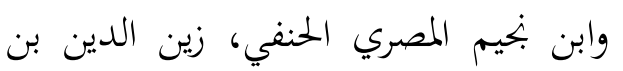

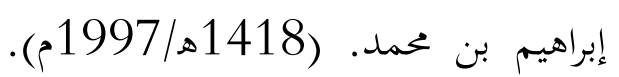

البحر الرائق شرح كنز الدقائق (في فروع

الحنفية). زكريا عميرات (محقق).

بيروت-لبنان: دار الكتب العلمية. ط1 1.

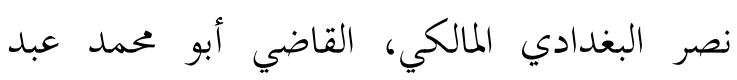
الوهاب بن علي. (1420هـ/1999م).

الإشراف على نكت مسائل الخلاف.

الحبيب بن طاهر (محقق). دار ابن حازم.

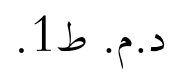

النووي، أبو زكريا ميي الدين يهيى بن شرف. (د.ت.). المجموع شرح المهذب. دار

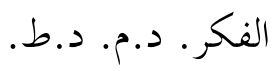
نووي، محمد بن عمر الجاوي. (1417ه). مراح لبيد لكشف معنى قرآن مجيد. محمد أمين الضناوى (محقق). بيروت: دار

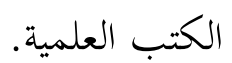

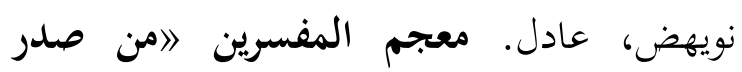

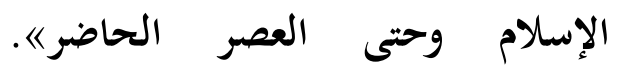

(1988/1409هـم) مُفتئ الجمهورية

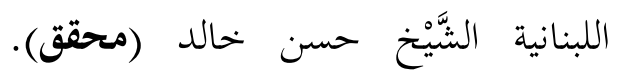
بيروت-لبنان: مؤسسة نويهض الثقافية. هورخروتية، ك. السنوك (د.ت.). تاريخ مكة المكرمة. الرياض: إدارة الملك عبد العزيز. د.ط. 